\title{
In vitro and in vivo anthelmintic activity of (-)-6,6'-dinitrohinokinin against schistosomula and juvenile and adult worms of Schistosoma mansoni
}

\author{
Ana C. Pereira ${ }^{\mathrm{a}, \mathrm{e}}$, Márcio L.A. e Silva ${ }^{\mathrm{a}}$, Julia Medeiros Souza ${ }^{\mathrm{a}}$, Rosangela S. de Laurentiz ${ }^{\mathrm{b}}$, \\ Vanderlei Rodrigues ${ }^{\mathrm{c}}$, Ana H. Januário ${ }^{a}$, Patrícia M. Pauletti ${ }^{\mathrm{a}}$, Denise C. Tavares ${ }^{\mathrm{a}}$, \\ Ademar A. Da Silva Filho ${ }^{\mathrm{d}}$, Wilson R. Cunha ${ }^{\mathrm{a}}$, Jairo K. Bastos ${ }^{\mathrm{e}}$, Lizandra G. Magalhães ${ }^{\mathrm{a}, *}$ \\ a Universidade de Franca, Núcleo de Pesquisas em Ciências Exatas e Tecnológicas, CEP 14404-600 Franca, SP, Brazil \\ ${ }^{\mathrm{b}}$ Universidade Estadual Paulista, Faculdade de Engenharia de Ilha Solteira, Departamento de Física e Química, CEP 15385-000, Ilha Solteira, SP, Brazil \\ c Universidade de São Paulo, Faculdade de Medicina de Ribeirão Preto, Departamento de Bioquímica e Imunologia, CEP 14049-900, Ribeirão Preto, SP, Brazil \\ d Universidade Federal de Juiz de Fora, Faculdade de Farmácia de Juiz de Fora, Departamento de Ciências Farmacêuticas, CEP 36036-900, Juiz de Fora, MG, \\ Brazil \\ e Universidade de São Paulo Faculdade de Farmácia de Ribeirão Preto, Departamento de Ciências Farmacêuticas, CEP 14030-000, Ribeirão Preto, SP, Brazil
}

\section{A R T I C L E I N F O}

\section{Article history:}

Received 17 October 2014

Received in revised form 2 June 2015

Accepted 6 June 2015

Available online 10 June 2015

\section{Keywords:}

Lignan

(-)-6,6'-Dinitrohinokinin

Schistosoma mansoni

\begin{abstract}
A B S T R A C T
The chemotherapy of schistosomiasis relies on the use of praziquantel. However, concerns over drug resistance have encouraged the search for new drug leads. This paper is the first report on the in vitro and in vivo activity of (-)-6,6'-dinitrohinokinin (DNK) against Schistosoma mansoni. In vitro, the lethal concentrations for $50 \%$ of parasites $\left(\mathrm{LC}_{50}\right)$ of DNK against adult worms were $103.9 \pm 3.6$ and $102.5 \pm 4.8 \mu \mathrm{M}$ at 24 and $72 \mathrm{~h}$, respectively. Scanning electron microscopy images showed extensive tegumental alterations such as peeling and smaller numbers of tubercles in the spine of adult worms. DNK also elicited high mortality of schistosomula, with LC50 values of $57.4 \pm 2.3,32.5 \pm 0.9$, and $20.4 \pm 1.2 \mu \mathrm{M}$ at 24,48 , and $72 \mathrm{~h}$, respectively. DNK displayed moderate activity against the juvenile liver parasite, with an $\mathrm{LC}_{50}$ value of $179.5 \pm 2.3 \mu \mathrm{M}$ at $72 \mathrm{~h}$. This compound reduced the total number of eggs by over $83 \%$, and it affected the development of eggs produced by adult worms. The selectivity index showed that at $24 \mathrm{~h}$, DNK was 8.5 and 15.4 times more toxic to the adult worms and schistosomula than to Chinese hamster lung fibroblast cells, respectively. Treatment of infected mice with DNK moderately decreased worm burden (33.8-52.3\%), egg production (40.7-60.0\%), and spleen and liver weights. Together, our results indicated that DNK presents moderate in vitro and in vivo activities against $S$. mansoni, and it might therefore be interesting to explore the structure-activity relationship of the antischistosomal activity of this compound.
\end{abstract}

(c) 2015 Elsevier B.V. All rights reserved.

\section{Introduction}

Schistosomiasis, also known as bilharzia, continues to be one of the main neglected tropical diseases (Gryseels et al., 2006; Hotez et al., 2007). According to the World Health Organization (WHO), this condition affects more than 200 million people worldwide, and an estimate of 700 million people are at risk of contracting this disease in 74 endemic countries. In addition, schistosomiasis causes

\footnotetext{
* Corresponding author. Fax: +55 1637118878 .

E-mail addresses: lizandra.magalhaes@unifran.edu.br, lizandraguidi@gmail.com (L.G. Magalhães)
}

the loss of 1.53 million disability-adjusted life years (Van der Werf et al., 2003; Steinmann et al., 2009; Rollinson et al., 2013).

The discovery of praziquantel (PZQ) in the 1970s and its introduction into the market in the 1980s were landmarks in the treatment of schistosomiasis. On the other hand, reduced cure rates and treatment failure have been reported in patients. Additionally, PZQ does not prevent reinfection, leading to repeated treatments in endemic areas and the existence of resistant strains. In addition, juvenile parasites (between 7 and 28 days old) are less susceptible to PZQ than adults (Sabah et al., 1986; Fallon and Doenhoff, 1994; Ismail et al., 1999; Pica-Mattoccia and Cioli, 2004). Because the implementation of measures to prevent and control schistosomiasis in endemic areas only takes effect in the long term, the development of new, safe, and effective schistosomicidal agents 


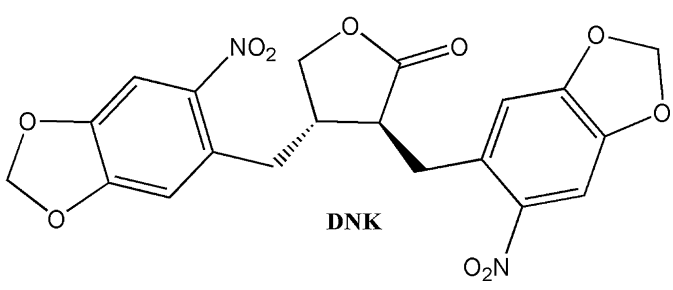

Fig. 1. Chemical structure of (-)-6,6'-dinitrohinokinin (DNK).

and therapeutic strategies that combine drugs has become an urgent matter (Ribeiro-dos-Santos et al., 2006).

Natural products are promising sources of novel potentially therapeutic substances and drug leads. The search for antiparasitic compounds obtained from natural sources has intensified, and plants continue to be a major supply of biologically active metabolites (Newman and Cragg, 2012). Folk medicine has used Piper cubeba, a species belonging to the family Piperaceae, to treat several diseases (Usia et al., 2005). Over the last few years, our team has evaluated the biological activity of extracts and compounds isolated from $P$. cubeba against neglected parasitic diseases (Saraiva et al., 2007; Esperandim et al., 2010; Magalhães et al., 2012). The compound 3,4-bis((6-nitrobenzo[d][1,3]dioxol5-yl) methyl)-dihydrofuran-2(3H)-one) ((-)-6,6'-dinitrohinokinin, DNK) is a dibenzylbutyrolactone lignan. This class of lignans consists of compounds that display a broad range of biological activities with therapeutic potential (Saraiva et al., 2007; Esperandim et al., 2010).

This paper is the first report on the in vitro and in vivo activity of (-)-6,6'-dinitrohinokinin (DNK) (Fig. 1) obtained by the partial synthesis of (-)-hinokinin against $S$. mansoni. The first step of this work evaluated the effect of DNK on schistosomula, juvenile liver worms and adult worms in vitro. In parallel, we examined the effect of DNK on pairing, egg production, egg development and the tegument of adult worms. In addition, the cytotoxic effect of DNK on Chinese hamster lung fibroblasts (V79 cells) was analyzed in vitro. Finally, the measurement of worm and egg burdens and the verification of liver and spleen pathologies has helped to evaluate the efficacy of DNK to treat mice infected with S. mansoni during the acute and chronic stages of schistosomiasis.

\section{Materials and methods}

\subsection{Partial synthesis of (-)-6,6'-dinitrohinokinin}

P. cubeba seeds from the fruits of P. cubeba L. (lot number S4113526) were purchased commercially from Suraji Bala Exports (Nova Delhi, India). By following a methodology described by our group (Silva et al., 2005), DNK was obtained by the partial synthesis of (-)-hinokinin, a semi-synthetic derivative of (-)-cubebin from $P$. cubeba. ${ }^{1} \mathrm{H}$ and ${ }^{13} \mathrm{C}$ Nuclear Magnetic Resonance (NMR) and spectral data helped to verify the chemical structure of DNK, which agreed with literature data (Silva et al., 2005). Both HPLC and spectroscopic analysis indicated that the purity of DNK was higher than $97 \%$.

\subsection{Animals and parasite}

The LE (Luiz Evangelista) strain of S. mansoni was used in all of the experiments. The parasite life cycle was maintained by passage through Biomphalaria glabrata snails and BALB/c mice (six-weekold females weighing 20-25 g).

Cercariae were obtained from infected snails exposed to light for $1 \mathrm{~h}$ after 38 days of infection according to the standard procedures of our laboratory. For the in vitro study, the juvenile liver worms or pairs of adult worms of $S$. mansoni were recovered from mice 21 days or 49 days after they had been infected with 200 cercariae, respectively. Subsequently, perfusion with RPMI 1640 medium (Gibco) of the livers and mesenteric veins of the mice was conducted under aseptic conditions (Smithers and Terry, 1965). For the in vivo study, groups of five BALB/c female mice ( 6 weeks old; $20-25 \mathrm{~g}$ ) were infected with $100 \mathrm{~S}$. mansoni cercariae. Infection was achieved by leaving the tail of the mice in contact with dechlorinated tap water containing cercariae for $1 \mathrm{~h}$ (Radke et al., 1971).

The Ethics Committees on Animal Care and Handling of the University of São Paulo and of the University of Franca authorized all of the experiments (approval number: 021/2009). Animal handling followed the guidelines for good animal practices in accordance with Brazilian legislation (CEUA, 11.794/2008).

\subsection{In vitro schistosomicidal assays}

\subsubsection{In vitro adult assay}

Two pairs of adult worms were placed in each well of a 24-well culture plate containing RPMI 1640 medium (Gibco) supplemented with antibiotics (penicillin $100 \mathrm{U} / \mathrm{mL}$ and streptomycin $100 \mu \mathrm{g} / \mathrm{mL}$ ) (Gibco) and 10\% bovine fetal serum (FBS) (Gibco). Plates were then incubated at $37^{\circ} \mathrm{C}$ for $24 \mathrm{~h}$ in a $5 \% \mathrm{CO}_{2}$ atmosphere. Subsequently, a stock solution of DNK at $100 \mathrm{mM}$ was then prepared in $10 \%$ dimethyl sulfoxide (DMSO) and culture medium and added to the wells at concentrations ranging from 12.5 to $200 \mu \mathrm{M}$ (5.5 to $89 \mu \mathrm{g} / \mathrm{mL}$ ). The parasites were kept for $72 \mathrm{~h}$ and monitored every $24 \mathrm{~h}$ using an inverted microscope. The phenotypic changes were scored on the basis of a viability scale ranging from 0 to 3 ( 3 = normal activity and no morphological changes; $2=$ slower activity and initial morphological changes; $1=$ minimal activity, occasional movement of the head and tail, and severe morphological changes; $0=$ death of all worms and severe morphological changes) (Ramirez et al., 2007). An inverted microscope also helped to evaluate alterations in the pairing of adult worms. The experiments were carried out in quadruplicate and repeated three times. RPMI 1640 medium or RPMI 1640 with $0.1 \%$ DMSO served as the negative control; PZQ (Sigma-Aldrich) at $12.5 \mu \mathrm{M}$ was the positive control.

\subsubsection{Scanning electron microscopy examination of the tegument}

To observe changes in the tegument of adult parasites, pairs of adult worms were cultured in DNK at $200 \mu \mathrm{M}$, or RPMI 1640 containing 0.1\% DMSO (negative control), or PZQ $12.5 \mu \mathrm{M}$ (positive control) for $24 \mathrm{~h}$, which was followed by fixation in $0.1 \mathrm{M}$ phosphate buffer ( $\mathrm{pH}$ 7.2) containing 3\% glutaraldehyde (Sigma-Aldrich) at $37^{\circ} \mathrm{C}$ for $2 \mathrm{~h}$. After this period, worms were washed three times with the same buffer and post-fixed in phosphate buffer containing $1 \%$ osmium tetroxide (Sigma-Aldrich) at room temperature for $1 \mathrm{~h}$. All worms were dehydrated in ethanol, washed several times in $100 \%$ ethanol, critical-point-dried in $\mathrm{CO}_{2}$, mounted on stubs, coated with gold, and examined under the Joel JSM-5200 scanning electron microscope operating at $25 \mathrm{kV}$. All of the measurements were taken in micrometers $(\mu \mathrm{m})$.

\subsubsection{In vitro study of the production and development of eggs}

One pair of adult worms was placed in each well of a 24-well culture plate and incubated with DNK for $72 \mathrm{~h}$, as described in Section 2.3.1. Then, the eggs were counted with the aid of an inverted microscope. To verify egg development, pairs of adult worms were cultivated as depicted in Section 2.3.1, in the absence of the tested compound, for two days. Next, the worms were removed, DNK was added at the same concentrations used above $(12.5$ to $200 \mu \mathrm{M}$ or 5.5 to $89 \mu \mathrm{g} / \mathrm{mL}$ ), and the eggs were incubated in DNK for five days. Eggs were classified as developed or non-developed as published by Michaels and Prata (1968). The experiments were performed 
in quadruplicate. Negative control experiments used RPMI 1640 medium or RPMI 1640 with $0.1 \%$ DMSO instead of DNK and were conducted in triplicate.

\subsubsection{In vitro juvenile liver worm assay}

For the juvenile liver parasite assay, two parasites (21 days old) were added to the RPMI 1640 medium (Gibco) as described above, and viability was evaluated every $24 \mathrm{~h}$ for $72 \mathrm{~h}$, with the aid of an inverted microscope, as suggested by Manneck et al. (2010). The experiments were performed in quadruplicate. Negative control experiments used RPMI 1640 medium or RPMI 1640 with $0.1 \%$ DMSO instead of DNK and were conducted in triplicate.

\subsubsection{In vitro schistosomula assay}

The parasites were obtained by mechanical transformation of cercariae, as reported by Harrop and Wilson (1993). One hundred schistosomula were added to each well of a 24 -well plate and incubated with RPMI 1640 medium supplemented with antibiotics (penicillin $100 \mathrm{UI} / \mathrm{mL}$ and streptomycin $100 \mu \mathrm{g} / \mathrm{mL}$ ) (Gibco) and $10 \%$ FBS (Gibco) at $37{ }^{\circ} \mathrm{C}$ for $24 \mathrm{~h}$ in $5 \% \mathrm{CO}_{2}$. After the adaptation of the schistosomula to the culture medium, DNK was added at the same concentrations described earlier in this work (12.5 to $200 \mu \mathrm{M}$ or 5.5 to $89 \mu \mathrm{g} / \mathrm{mL}$ ). The cultures were incubated under the same conditions $\left(37^{\circ} \mathrm{C}, 24 \mathrm{~h}, 5 \% \mathrm{CO}_{2}\right)$, and the schistosomula viability was assessed every $24 \mathrm{~h}$ for $72 \mathrm{~h}$ by means of an inverted microscope. Parasites were considered dead when they became immotile and presented with massive structural damage in the schistosomula, as reported by Manneck et al. (2010). The experiments were carried out in quadruplicate. Negative control experiments used RPMI 1640 medium or RPMI 1640 with 0.1\% DMSO instead of DNK and were conducted in triplicate.

\subsection{Cytotoxicity assay}

Cytotoxicity was measured with the aid of the in vitro Toxicology Colorimetric Assay Kit (XTT; Roche Diagnostics) according to the manufacturer's instructions. Chinese hamster lung fibroblasts (V79 cells) were cultured in HAM-F10 (Sigma-Aldrich) and Dulbecco's Modified Eagle's Medium (DMEM) (Sigma-Aldrich) (1:1) supplemented with $10 \%$ FBS, antibiotics $(100 \mu \mathrm{g} / \mathrm{mL}$ streptomycin and $50 \mathrm{U} / \mathrm{mL}$ penicillin) and $2.38 \mathrm{mg} / \mathrm{mL}$ HEPES (4-(2hydroxyethyl)-1-piperazineethanesulfonic acid) (Sigma-Aldrich) at $37^{\circ} \mathrm{C}$ with $5 \% \mathrm{CO}_{2}$. For these experiments, cells $\left(10^{4}\right.$ cells/well) were plated in 96-well microplates. Each well received $100 \mu \mathrm{L}$ DMEM medium (Sigma-Aldrich) containing DNK at concentrations ranging from 6.25 to $400 \mu \mathrm{M}(2.7$ to $178 \mu \mathrm{g} / \mathrm{mL})$ dissolved in $0.2 \%$ DMSO for $24 \mathrm{~h}$. Negative (without treatment), solvent (0.2\% DMSO), and positive (25\% DMSO) controls were included. After incubation at $37^{\circ} \mathrm{C}$ for $24 \mathrm{~h}$, the medium was removed, and the cells were washed twice with $100 \mu \mathrm{L}$ of phosphate buffered saline (PBS) and exposed to $100 \mu \mathrm{L}$ of HAM-F10 medium without phenol red. Then, $50 \mu \mathrm{L}$ of XTT was added to each well. The microplates were covered and incubated at $37^{\circ} \mathrm{C}$ for $17 \mathrm{~h}$. The absorbance of the samples was determined on a multiplate reader (Tecan - SW Magellan vs 5.03 STD 2PC) at a test wavelength of $492 \mathrm{~nm}$ and a reference wavelength of $690 \mathrm{~nm}$. Two experiments were performed in triplicate.

\subsection{In vivo treatment}

\subsubsection{Pre-toxicity assessment}

A pre-toxicity test was performed as suggested by Ramirez et al. (2007). For this purpose, four uninfected BALB/c female mice were employed. DNK was dissolved in DMSO and injected (i.p.) in mice as follows: $50 \mathrm{mg} / \mathrm{kg}$ at $0 \mathrm{~h}, 150 \mathrm{mg} / \mathrm{kg}$ at $2 \mathrm{~h}, 300 \mathrm{mg} / \mathrm{kg}$ at $4 \mathrm{~h}$, and
$500 \mathrm{mg} / \mathrm{kg}$ at $8 \mathrm{~h}$. The assay was stopped after $10 \mathrm{~h}$ because all of the mice had died.

\subsubsection{Treatment design}

DNK was dissolved in $100 \mu \mathrm{L}$ of DMSO and administered to groups of 5 mice by intraperitoneal injection (i.p.) at 10, 50, or $100 \mathrm{mg} / \mathrm{kg}$ for five consecutive days per treatment group, based on the treatment scheme proposed by Sayed et al. (2008): Treatment 1 started 1 day after infection (skin-stage parasites), treatment 2 started 23 days after infection (juvenile parasites), and treatment 3 started 37 days after infection (adult worms) after infection. The negative control consisted of one group of five $S$. mansoni-infected mice that received DMSO in amounts equivalent to the amount of DMSO administered to the treated animals.

All mice were killed with an overdose of sodium pentobarbital $(250 \mathrm{mg} / \mathrm{kg})$. Worms were collected from all groups 49 days after infection of the mice by perfusion of the hepatic portal and the mesenteric veins according to Smithers and Terry (1965). The collected worms were counted under a dissecting microscope. To evaluate the number of eggs in the liver, liver tissue was weighed and digested by overnight incubation in $5 \% \mathrm{KOH}$ at $37^{\circ} \mathrm{C}$, as suggested by Cheever (1968). The digested tissue suspensions were centrifuged at $15200 \times \mathrm{g}$, and the eggs present in the pellet were counted on microscope slides under $10 \times$ magnification. To evaluate the antipathologic effect, the liver and spleen from infected control mice and treated mice were weighed and compared.

\subsection{Statistical analysis}

All results are expressed as the mean \pm S.E.M. Data were statistically analyzed by one-way analysis of variance followed by Dunnett's comparison. The statistical tests were performed with the aid of GraphPad Prism (version 5.0) software.

Lethal Concentration $\left(\mathrm{LC}_{50}\right)$ and Cytotoxic Concentration $\left(\mathrm{CC}_{50}\right)$ values, which refer to the schistosomicidal and cytotoxic activities of DNK in vitro, respectively, were calculated from a nonlinear regression dose-response inhibition graph. The Selectivity Indices (SI) were determined by dividing the $\mathrm{CC}_{50}$ of the V79 cells cytotoxicity data by the $\mathrm{LC}_{50}$ of the schistosomicidal assay. The percentage of worm and egg reduction in vivo was calculated by means of the following equation:

$\%$ reduction $=\left[\frac{\text { value of untreated controlgroup }- \text { value oftreatment group }}{\text { value of untreated control group }}\right] \times 100 \%$

\section{Results}

\subsection{In vitro effect of (-)-6,6'-dinitrohinokinin against $\mathrm{S}$. mansoni}

3.1.1. In vitro effect of (-)-6,6'-dinitrohinokinin on pairs of S. mansoni adult worms

In vitro, DNK at $200 \mu \mathrm{M}$ killed $100 \%$ of the adult worms within $24 \mathrm{~h}$ (Fig. 2) and afforded $\mathrm{LC}_{50}$ values of $103.9 \pm 3.6$ and $102.5 \pm 4.8 \mu \mathrm{M}$ at 24 and $72 \mathrm{~h}$, respectively (Table 1). DNK at $100 \mu \mathrm{M}$ drastically diminished parasite movement within $24 \mathrm{~h}$. At all other concentrations (except $12.5 \mu \mathrm{M}$ ), DNK reduced parasite movement and caused some morphological alterations (Fig. 3). Incubation with DNK at $200 \mu \mathrm{M}$ severely damaged the tegument of both female and male adult parasites. Peeling of the tegument occurred within $24 \mathrm{~h}$. In the case of the male parasite, there was a severe reduction in the number of tubercles in their spine (Fig. $3 \mathrm{~A}$ and $\mathrm{B})$.

There were no modifications in the viability (Fig. 2) or tegument (Fig. 3C and D) of the female and male adult parasites belonging to the negative control groups (RPMI 1640 or RPMI $1640+0.1 \%$ 


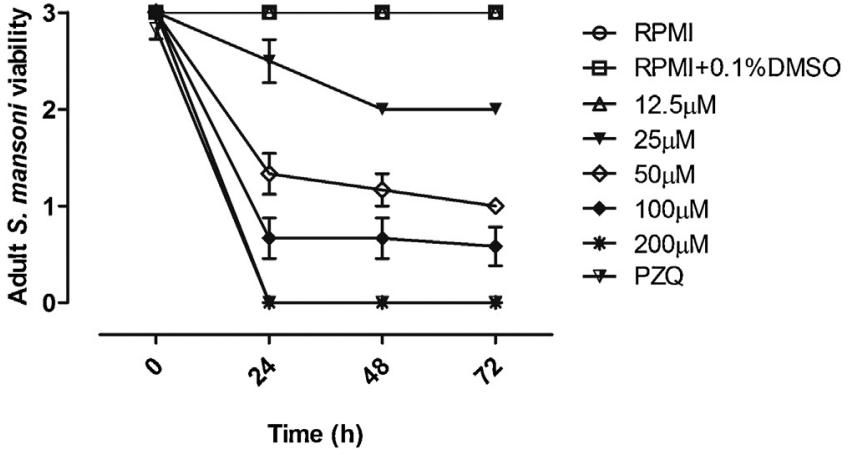

Fig. 2. In vitro effect of lignan (-)-6,6'-dinitrohinokinin (DNK) on the viability of $S$. mansoni adult worms. Pairs of adult worms were incubated with DNK, and the viability was monitored every $24 \mathrm{~h}$ for $72 \mathrm{~h}$ with the aid of a viability scale of $0-3$ ( 3 =normally active and no morphological changes; 2 =slower activity and initial morphological changes; 1 = minimal activity, occasional movement of the head and tail, and severe morphological changes; 0 = death of all worms and severe morphological changes). Adult worms belonging to the control groups were incubated with praziquantel (PZQ) at $12.5 \mu \mathrm{M}$ (positive control) or with RPMI 1640 medium only or with RPMI 1640 containing 0.1\% DMSO (negative controls). Values are expressed as the mean \pm S.E.M of three independent experiments (a total of 24 pairs of adult worms were scored at each concentration).
DMSO). On the other hand, incubation of worms with PZQ $(12.5 \mu \mathrm{M}$ or $3.9 \mu \mathrm{g} / \mathrm{mL}$ ) resulted in $100 \%$ parasite mortality within $24 \mathrm{~h}$ (Fig. 2). Blebs emerged in the male parasite tegument, and peeling occurred in the female parasite within $24 \mathrm{~h}$ of incubation (Fig. 3E and F).

\subsubsection{In vitro effect of (-)-6,6'-dinitrohinokinin on the production and development of eggs by pairs of adult worms}

The effect of DNK on adult worms motivated the investigation of the in vitro activity of DNK against the production and development of eggs. At concentrations higher than $25 \mu \mathrm{M}$, DNK separated all of the $S$. mansoni couples after $24 \mathrm{~h}$ of incubation and reduced the total number of eggs by over $83 \%$ (Fig. 4 A). On the other hand, parasites remained coupled at a DNK concentration of $12.5 \mu \mathrm{M}$, and egg production did not differ significantly from the egg production in the negative control groups. At concentrations of 50,100, and $200 \mu \mathrm{M}$, DNK impaired the development of eggs produced by adult worms (Fig. 4B).

\subsubsection{In vitro effect of (-)-6,6'-dinitrohinokinin on juvenile liver worm and schistosomula mortality}

In the case of juvenile liver worms, DNK yielded $\mathrm{LC}_{50}$ values of $522.8 \pm 4.7,226.3 \pm 3.2$, and $179.5 \pm 2.3 \mu \mathrm{M}$ at 24,48 , and $72 \mathrm{~h}$ of incubation (Table 1). The negative control group showed normal viability. Moreover, the activity against mechanically transformed schistosomula parasites was high after incubation with DNK, providing $\mathrm{LC}_{50}$ values of $57.4 \pm 2.3,32.5 \pm 0.9$, and $20.4 \pm 1.2 \mu \mathrm{M}$ at

Table 1

In vitro effect of (-)-6,6'-dinitrohinokinin S. mansoni and V79 cells.

\begin{tabular}{|c|c|c|c|c|c|}
\hline & \multicolumn{3}{|l|}{$\mathrm{LC}_{50}(\mu \mathrm{M})^{\mathrm{a}}$} & \multirow{2}{*}{$\begin{array}{l}\mathrm{CC}_{50}(\mu \mathrm{M})^{\mathrm{b}} \\
24 \mathrm{~h}\end{array}$} & \multirow[t]{2}{*}{$\mathrm{SI} / 24 \mathrm{~h}^{\mathrm{c}}$} \\
\hline & $24 \mathrm{~h}$ & $48 \mathrm{~h}$ & $72 \mathrm{~h}$ & & \\
\hline Adult worm & $103.9 \pm 3.6$ & $103.9 \pm 3.6$ & $102.5 \pm 4.8$ & & 8.5 \\
\hline Juvenile liver worm & $522.8 \pm 4.7$ & $226.3 \pm 3.2$ & $179.5 \pm 2.3$ & & 1.7 \\
\hline Schistosomula & $57.4 \pm 2.3$ & $32.5 \pm 0.9$ & $20.4 \pm 1.2$ & & 15.4 \\
\hline V79 cells & & & & $885.5 \pm 0.2$ & \\
\hline
\end{tabular}

${ }^{a} \mathrm{LC}_{50}$ lethal concentration.

b $\mathrm{CC}_{50}$ cytotoxic concentration.

c SI selectivity index between V79 cells (Chinese hamster lung fibroblast cells) and the parasite stages.
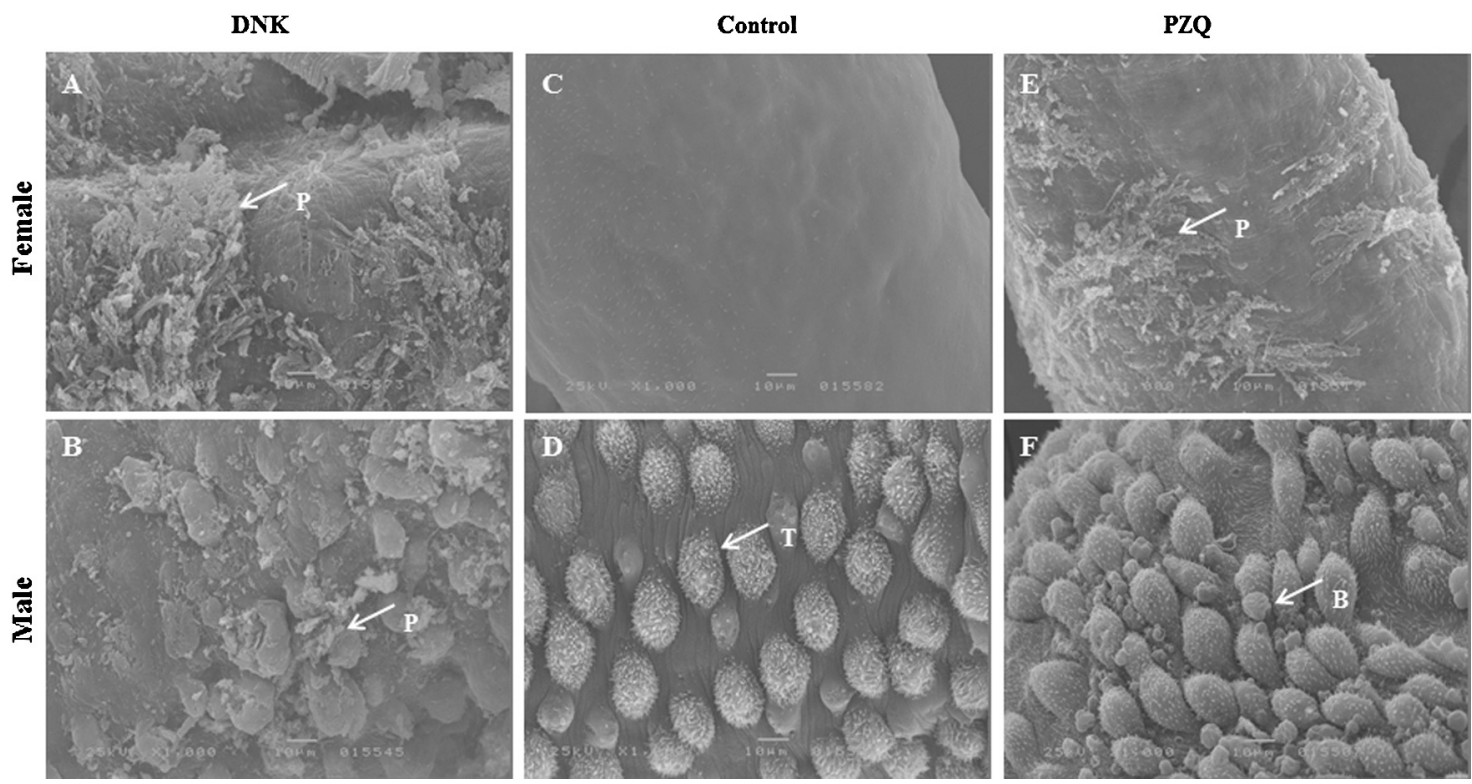

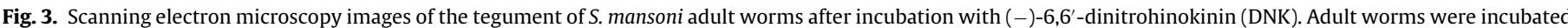

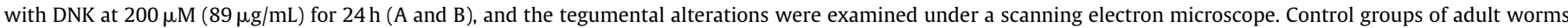

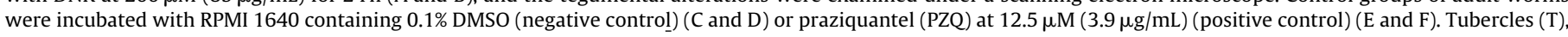
Peeling (P), Bubbles (B). 

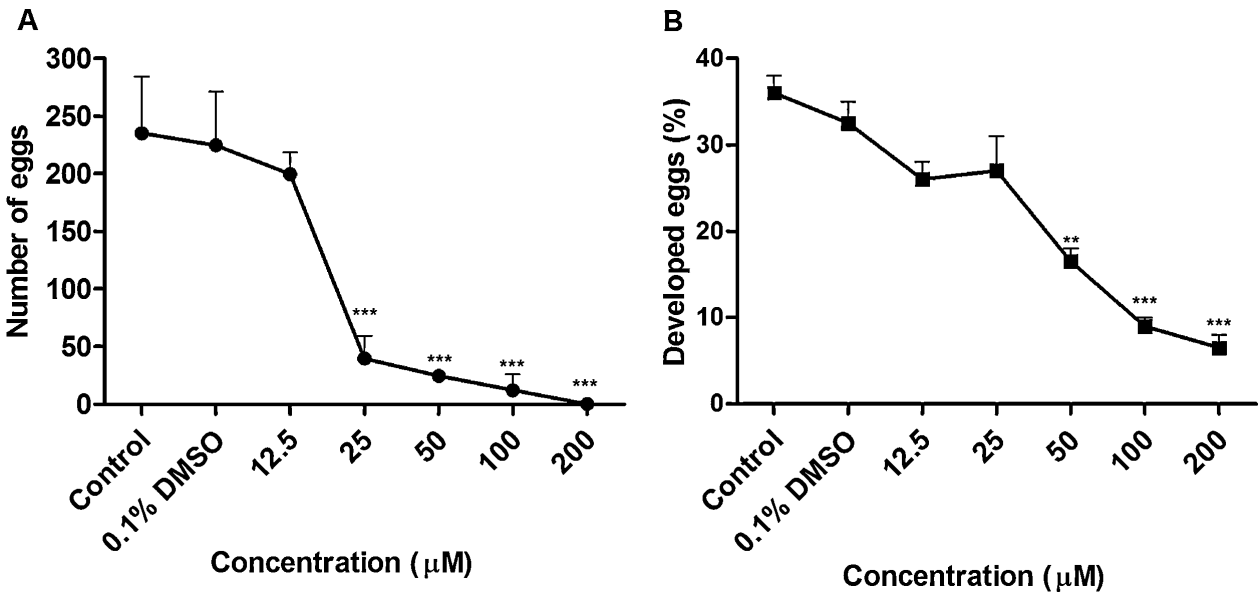

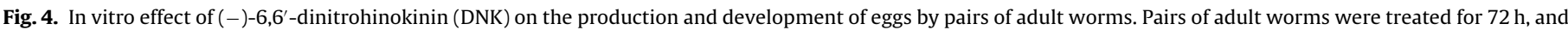

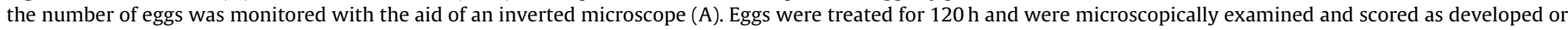

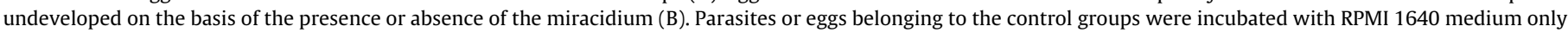

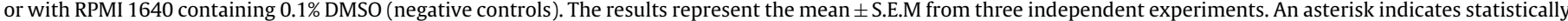
significant differences compared with the negative control group (RPMI 1640 medium only) $\left({ }^{* *} P<0.01,{ }^{* * *} P<0.001\right)$.

24,48 , and $72 \mathrm{~h}$, respectively (Table 1 ). In the absence of DNK, the viability of schistosomula was normal.

\subsection{In vitro evaluation of (-)-6,6'-dinitrohinokininon cytotoxicity to mammalian cells}

Incubation of different concentrations of DNK with Chinese hamster lung fibroblast cells (V79 cells) helped to ascertain the cytotoxicity of DNK in vitro. Cell viability was monitored for $24 \mathrm{~h}$. No cytotoxicity was observed at the evaluated concentrations, and the viability at higher DNK concentrations $(400 \mu \mathrm{M})$ was approximately $90 \%$. The calculated $\mathrm{CC}_{50}$ was $885.5 \pm 0.21 \mu \mathrm{M}$ (Table 1 ). The selectivity index (SI) determined at $24 \mathrm{~h}$, which indicated the toxicity of DNK toward the parasite compared to the toxicity of DNK toward the V79 cells, demonstrated that DNK was 8.5 and 15.4 times more toxic to the adult parasite and schistosomula than to V79 cells, respectively. On the other hand, DNK was only 1.7 times more toxic to the juvenile liver parasite than to V79 cells (Table 1).

\subsection{In vivo effect of (-)-6,6'-dinitrohinokinin against $\mathrm{S}$. mansoni-infected mice}

Although in vitro assays are not considered suitable to cover all aspects of the anthelminthic activities of drugs, they provide the first evidence of anti-helminthic effects and give insight into their mode of action (Holtfreter et al., 2011). For this reason, we undertook in vivo studies to evaluate the activity of DNK against $S$. mansoni-infected mice.

The pre-toxicity assessment for DNK on uninfected BALB/c mice showed that the highest tolerated dose was $500 \mathrm{mg} / \mathrm{Kg}$. The in vivo assay involved intraperitoneal injections (i.p.) of DNK at 10, 50, or $100 \mathrm{mg} / \mathrm{kg}$ daily for five consecutive days as follows: Treatment 1 started 1 day after infection (skin-stage parasites), treatment 2 started 23 days after infection (juvenile parasites), and treatment 3 started 37 days after infection (adult worms).

As listed in Table 2, all treatments reduced the total number of worms moderately compared with the negative control. Treatment 1 markedly decreased the total number of worms at all dosages by $33.8,44.6$, and $47.9 \%$ at 10,50 , and $100 \mathrm{mg} / \mathrm{kg} / \mathrm{day}$, respectively, with no significant differences among the doses. Treatment 2 significantly lowered the total number of worms by 36.2, 52.0, and $52.3 \%$ at 10,50 , and $100 \mathrm{mg} / \mathrm{kg} / \mathrm{day}$, respectively, but the doses of $50 \mathrm{mg} / \mathrm{kg} /$ day and $100 \mathrm{mg} / \mathrm{kg} /$ day were more effective com- pared with $10 \mathrm{mg} / \mathrm{kg} /$ day. Treatment 3 considerably diminished the total number of worms by $39.9,48.9$, and $48.3 \%$ at 10,50 , and $100 \mathrm{mg} / \mathrm{kg} /$ day, respectively, with no significant differences among the doses. It was possible to recover an equal number of male and female worms from the treated animals, which indicated that DNK was equally active against both male and female worms.

DNK significantly decreased the number of eggs per gram of tissue in the case of treatments 1 and 2 compared with the negative control. Treatment 1 markedly reduced the number of eggs per gram of tissue by $40.7,47.8$, and $47.9 \%$ at 10,50 , and $100 \mathrm{mg} / \mathrm{kg} /$ day, respectively. Treatment 2 promoted the highest activity. It decreased the number of eggs per gram of tissue by 52.5 , 53.6 , and $60.0 \%$ at 10,50 , and $100 \mathrm{mg} / \mathrm{kg} /$ day, respectively. In addition, the spleen and liver weights dropped during treatments 1 and 2 compared with the negative control, which culminated in reduced hepatomegaly and splenomegaly. Treatment 3 did not lower the number of eggs or the spleen and liver weights (Table 2).

\section{Discussion}

The present study reported how DNK affected S. mansoni in vitro and in vivo. Among the several classes of plant-derived secondary metabolites, lignans constitute a class that displays a wide spectrum of biological activities (Apers et al., 2003), including their action against parasites that cause neglected tropical diseases such as trypanosomiasis (Saraiva et al., 2007; Esperandim et al., 2010) and leishmaniasis (Royo et al., 2003). In a previous work, our group found that (-)-cubebin from $P$. cubeba (used in the semi-synthesis of DNK in the present work) did not kill S. mansoni but minimized the movement that occurred at concentrations of 100 and $200 \mu \mathrm{M}$. In addition, studies have shown that DNK acts against oral microorganisms (Silva et al., 2007) and possesses significant anti-inflammatory and analgesic activities (Da Silva et al., 2005). It has been suggested that the carbonyl group at C-9 and the introduction of polar groups such as $\mathrm{NO}_{2}$ in the aromatic rings benefit biological activities. Nevertheless, nitro compounds may undergo redox cycling and cause host toxicity. Interestingly, DNK was not cytotoxic to V79 mammalian cells in vitro. Many therapeutic drugs available on the market bear nitro groups, such as metronidazole, nitrofural, oxamniquine, furazolidone, chloramphenicol, nitrofural, nitrofurazone, and clonazepam, among others. Paula et al. (2009) reported that the toxicity of nitro compounds depends not only on their chemical structure but also on dose and exposure time. 
Table 2

In vivo effect of (-)-6,6'-dinitrohinokin against S. mansoni infected mice.

\begin{tabular}{|c|c|c|c|c|c|c|c|c|c|}
\hline \multirow[t]{2}{*}{$\begin{array}{l}\text { Groups and doses } \\
(\mathrm{mg} / \mathrm{kg})^{\mathrm{a}}\end{array}$} & \multicolumn{4}{|c|}{$\begin{array}{l}\text { Mean worm } \\
\text { burden } \pm \text { S.E.M }\end{array}$} & \multirow{2}{*}{$\begin{array}{l}\text { Reduction of total } \\
\text { worm burden }^{b} \\
\%\end{array}$} & \multirow[t]{2}{*}{$\begin{array}{l}\text { Liver weight } \\
\text { (g) }\end{array}$} & \multirow[t]{2}{*}{$\begin{array}{l}\text { Spleen } \\
\text { weight (g) }\end{array}$} & \multirow[t]{2}{*}{$\begin{array}{l}\text { Number of eggs/g } \\
\text { liver tissue }\end{array}$} & \multirow{2}{*}{$\begin{array}{l}\text { Reduction of } \\
\text { eggs }^{b} \\
\%\end{array}$} \\
\hline & Male & Female & Couple & Total & & & & & \\
\hline Control & $19.2 \pm 3.1$ & $16.4 \pm 2.4$ & $12.2 \pm 1.9$ & $59.6 \pm 6.3$ & & $1.74 \pm 0.11$ & $0.71 \pm 0.09$ & $74881 \pm 4694$ & \\
\hline $\mathrm{T} 110$ & $11.6 \pm 2.3$ & $10.6 \pm 5.3$ & $8.6 \pm 1.8$ & $39.4 \pm 4.0^{* * *}$ & 33.8 & $1.43 \pm 0.18^{*}$ & $0.52 \pm 0.06^{* * *}$ & $44392 \pm 4702^{* * *}$ & 40.7 \\
\hline T1 50 & $11.6 \pm 3.3$ & $9.4 \pm 2.5$ & $6.0 \pm 0.7$ & $33.0 \pm 2.0^{* * *}$ & 44.6 & $1.47 \pm 0.25^{*}$ & $0.49 \pm 0.04^{* * *}$ & $39056 \pm 1257^{* * *}$ & 47.8 \\
\hline T1 100 & $13.8 \pm 3.2$ & $8.4 \pm 4.4$ & $6.0 \pm 2.0$ & $31.0 \pm 1.5^{* * *}$ & 47.9 & $1.54 \pm 0.09^{*}$ & $0.47 \pm 0.03^{* * *}$ & $38969 \pm 6141^{* * *}$ & 47.9 \\
\hline T2 10 & $13.0 \pm 3.3$ & $9.0 \pm 2.9$ & $8.0 \pm 2.2$ & $38.0 \pm 6.4^{* * *}$ & 36.2 & $1.38 \pm 0.06^{*}$ & $0.44 \pm 0.03^{* * *}$ & $34742 \pm 3056^{* * *}$ & 52.5 \\
\hline T2 50 & $11.0 \pm 3.0$ & $9.2 \pm 2.6$ & $5.0 \pm 2.2$ & $28.6 \pm 5.5^{* * *}$ & 52.0 & $1.40 \pm 0.10^{*}$ & $0.42 \pm 0.02^{* * *}$ & $35542 \pm 3269^{* * *}$ & 53.6 \\
\hline T2 100 & $10.6 \pm 2.7$ & $8.2 \pm 4.2$ & $4.8 \pm 2.2$ & $28.4 \pm 5.3^{* * *}$ & 52.3 & $1.43 \pm 0.11^{*}$ & $0.45 \pm 0.04^{* * *}$ & $29934 \pm 1466^{* * *}$ & 60.0 \\
\hline T3 10 & $13.2 \pm 0.8$ & $10.2 \pm 3.9$ & $6.2 \pm 1.4$ & $35.8 \pm 4.7^{* * *}$ & 39.9 & $1.69 \pm 0.11$ & $0.65 \pm .0 .2$ & $60341 \pm 9598$ & 19.0 \\
\hline T3 50 & $10.2 \pm 2.3$ & $9.4 \pm 1.5$ & $6.4 \pm 2.8$ & $30.4 \pm 3.3^{* * *}$ & 48.9 & $1.68 \pm 0.13$ & $0.64 \pm 0.04$ & $62205 \pm 4103$ & 16.9 \\
\hline T3 100 & $11.4 \pm 2.6$ & $10.2 \pm 2.2$ & $4.6 \pm 2.0$ & $30.8 \pm 4.8^{* * *}$ & 48.3 & $1.70 \pm 0.09$ & $0.63 \pm 0.05$ & $60541 \pm 1297$ & 19.1 \\
\hline
\end{tabular}

Data are expressed as the mean \pm S.E.M; Asterisk indicates statistically significant differences compared with the negative control group $\left({ }^{*} P<0.05 .{ }^{* * *} P<0.001\right)$.

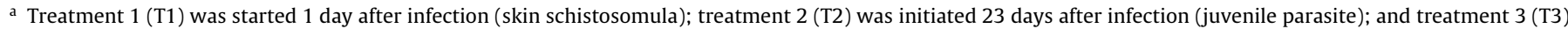
was started 37 days after infection (adult worms parasite).

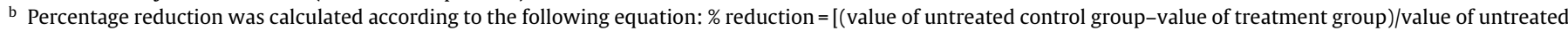
control group] X $100 \%$.

In addition, the selectivity index (SI) parameter is relevant. Indeed, values higher than 10 could suggest that a product is safer for use in mammalian hosts (Lenta et al., 2007). Herein, the SI was 15.4 and 8.5 for schistosomula and pairs of adult worms, respectively.

Some in vitro studies on natural products have reported that male $S$. mansoni worms are often more susceptible than female worms (Sanderson et al., 2002; De Melo et al., 2011), whereas other investigations have not mentioned any differences between male and female worms (Manneck et al., 2010; Moraes et al., 2011). Previous studies have stated that the tegument can be a target for the development of antischistosomal drugs. In fact, most of the compounds used against schistosomes, such as PZQ (Shuhua et al., 2000), mefloquine (Manneck et al., 2010), and artemether (Xiao et al., 2007), can act by damaging the tegument apart from displaying other mechanisms of action. In the present work, the results obtained in vitro showed that DNK was active against both male and female adult worms and severely damaged the tegument of adult worms. At concentrations higher than $25 \mu \mathrm{M}$, DNK elicited high mortality of the mechanically transformed schistosomula parasites, an outcome that was similar to the effect observed after incubation of schistosomula with mefloquine, for instance (Manneck et al., 2010).

Paired Schistosome couples that remain in the blood system of vertebrate hosts prompt high oviposition rates, which results in immunopathological lesions characterized by inflammation and fibrosis in the target organ (Kunz, 2001). In addition to playing a role in the pathological aspects of schistosomiasis, the developed eggs are crucial for the transmission of this infection (Freitas et al., 2007). Here, DNK successfully separated all of the S. mansoni couples, reduced the number of eggs, and decreased the percentage of egg development in vitro.

During the in vivo assay, we used the scheme for the treatment based by Sayed et al. (2008) and all treatments and DNK doses reduced the worm burden by 33.8 to $52.3 \%$. The applied administration protocol was that suggested by the WHO for a primary in vivo screening study (Ramirez et al., 2007) and by other investigations (Abdulla et al., 2007; Sayed et al., 2008; Allan et al., 2009 Aires et al., 2014). Additionally, in vivo treatments 1 and 2 caused a reduction in the number of eggs per gram of tissue and consequently a reduction of the liver and spleen weight. The reduction of eggs in the tissues in treated mice may be attributed to the reduction in worm burden as a result of DNK treatment or the present low productivity of the female.

Compared to our work, other studies of schistosomicidal activity have reported on similar or higher reductions in the number of adult worms and eggs (Abdulla et al., 2007; Allan et al., 2009 Aires et al., 2014). The results obtained with the three doses of DNK administered to mice did not evidence any significant correlation between dose and response, probably because the pharmacokinetic parameters can be involved with the lack of correlation between dose and response. In addition, Resende et al. (2010) did not find any dose-response correlation when they conducted the micronuclei test for (-)-hinokinin, a semi-synthetic compound derived from (-)-cubebin. Therefore, pharmacokinetic studies, measuring drug concentrations in the body and the target organs, might aid in the evaluation of DNK in vivo. The present study did not assay the in vivo effect of PZQ because administration of this drug at $50 \mathrm{mg} / \mathrm{kg}$ for five consecutive days reduces the number of adult worms by more than $90 \%$ (Aires et al., 2013).

In conclusion, this first report on the schistosomicidal activity of DNK indicated that this compound possesses moderate in vitro and in vivo activities against S. mansoni. Several structure-activity relationship (SAR) studies have been conducted (Menezes et al., 2012; Wang et al., 2013) to identify the best candidates to treat schistosomiasis. Considering the results obtained here, it might be interesting to explore the structure-activity relationship of its antischistosomal activity. Another possibility would be to use DNK in association with PZQ, which could give rise to better activity (synergism) and minimize the development of drug resistance by the parasite.

\section{Acknowledgments}

The authors are grateful to National Council for Scientific and Technological Development, Brazil - CNPq for fellowships and São Paulo Research Foundation, Brazil -FAPESP for financial support and fellowships (Processes FAPESP: 1998/14956-7, 2010/17378-8, 2011/10179-2 and 2009/15207-4). Electron Microscopy Laboratory in Ribeirão Preto, University of São Paulo, Brazil, for their support with the scanning electron microscopy examination. The authors are also thankful to Elenice Aparecida Macedo and Olinda Mara Brigatto for their technical support.

\section{References}

Abdulla, M.H., Lim, K.C., Sajid, M., McKerrow, J.H., Caffrey, C.R., 2007. Schistosomiasis mansoni: novel chemotherapy using a cysteine protease inhibitor. Plos Med. 4, e14.

Apers, S., Vlietinck, A., Pieters, L., 2003. Lignans and neolignans as lead compounds. Phytochem. Rev. 2, 201-217. 
Aires, A.L., Ximenes, E.C., Barbosa, V.X., Góes, A.J., Souza, V.M., Albuquerque, M.C., 2014. ó-Lapachone: a naphthoquinone with promising antischistosomal properties in mice. Phytomedicine 21 (3), 261-267.

Cheever, A.W., 1968. Conditions affecting the accuracy of potassium hydroxide digestion techniques for counting Schistosoma mansoni eggs in tissues. Bull. World Health Organ. 39, 328-331.

Da Silva, R., De Souza, G.H., Da Silva, A.A., De Souza, V.A., Pereira, A.C., Royo, V.A De Silva, M.L.A., Donate, P.M., De Matos Araújo, A.L., Carvalho, J.C., Bastos, J.K. 2005. Synthesis and biological activity evaluation of lignan lactones derived from (-)-cubebin. Bioorg. Med. Chem. Lett. 15 (4), 1033-1037.

De Melo, N.I., Magalhães, L.G., De Carvalho, C.E., Wakabayashi, K.A., De Paula Aguiar, G., Ramos, R.C., Mantovani, A.L., Turatti, I.C., Rodrigues, V., Groppo, M. Cunha, W.R., Veneziani, R.C., Crotti, A.E., 2011. Schistosomicidal activity of the essential oil of Ageratum conyzoides L (Asteraceae) against adult Schistosoma mansoni worms. Molecules 16, 762-773.

Esperandim, V.R., Da Silva Ferreira, D., Saraiva, J., Silva, M.L., Costa, E.S., Pereira, A.C., Bastos, J.K., De Albuquerque, S., 2010. Reduction of parasitism tissue by treatment of mice chronically infected with Trypanosoma cruzi with lignano lactones. Parasitol. Res. 107, 525-530.

Fallon, P.G., Doenhoff, M.J., 1994. Drug-resistant schistosomiasis, resistance to praziquantel and oxamniquine induced in Schistosoma mansoni in mice is drug specific. Am. J. Trop. Med. Hyg. 51, 83-88.

Freitas, T.C., Jung, E., Pearce, E.J., 2007. TGF- $\beta$ Signaling controls embryo development in the parasitic flatworm Schistosoma mansoni. PLoS Pathog. 3 , 489-497.

Gryseels, B., Polman, K., Clerinx, J., Kestens, L., 2006. Human schistosomiasis. Lancet 368, 1106-1118.

Harrop, R., Wilson, R.A., 1993. Protein synthesis and release by culture of schistosomula of Schistosoma mansoni. Parasitology 103, 265-274.

Holtfreter, M.C., Loebermann, M., Klammt, S., Sombetzki, M., Bodammer, P., Riebold, D., Kinzelbach, R., Reisinger, E.C., 2011. Schistosoma mansoni, schistosomicidal effect of mefloquine and primaquine in vitro. Exp. Parasitol. $127,270-276$

Hotez, P.J., Molyneux, D.H., Fenwick, A., Kumaresan, J., Sachs, S.E., Sachs, J.D., Savioli, L., 2007. Control of neglected tropical diseases. N. Engl. J. Med. 357 1018-1027.

Ismail, M., Botros, S., Metwally, A., William, S., Farghally, A., Tao, L.F., Day, T.A., Bennett, J.L., 1999. Resistance to praziquantel, direct evidence from Schistosoma mansoni isolated from Egyptian villagers. Am. J. Trop. Med. Hyg. 6, 932-935.

Kunz, W., 2001. Schistosome male-female interaction, induction of germ-cel differentiation. Trends Parasitol. 17, 227-231.

Lenta, B.N., Vonthron-Sénécheau, C.R., Sohd, F., Tantangmo, F., Ngouela, S., Kaiser, M., Tsamo, E., Anton, R., Weniger, B., 2007. In vitro antiprotozoal activities and cytotoxicity of some selected of some selected Cameroonian medicinal plants. J. Ethnopharmacol. 111, 8-12.

Magalhães, L.G., De Souza, J.M., Wakabayashi, K.A., Laurentiz, R.S., Vinhólis, A.H., Rezende, K.C., Simaro, G.V., Bastos, J.K., Rodrigues, V., Esperandim, V.R. Ferreira, D.S., Crotti, A.E., Cunha, W.R., Silva, M.L., 2012. In vitro efficacy of the essential oil of Piper cubeba L (Piperaceae) against Schistosoma mansoni. Parasitol. Res. 110, 1747-1754.

Manneck, T., Haggenmüller, Y., Keiser, J., 2010. Morphological effects and tegumental alterations induced by mefloquine on schistosomula and adult flukes of Schistosoma mansoni. Parasitology 137, 85-98.

Menezes, C.M., Rivera, G., Alves, M.A., Do Amaral, D.N., Thibaut, J.P., Noël, F., Barreiro, E.J., Lima, L.M., 2012. Synthesis, biological evaluation, and structure-activity relationship of clonazepam, meclonazepam, and. 1,4-benzodiazepine compounds with schistosomicidal activity. Chem. Biol. Drug. Des. 79 (6), 943-949.

Moraes, J., Nascimento, C., Lopes, P.O., Nakano, E., Yamaguchi, L.F., Kato, M.J. Kawano, T., 2011. Schistosoma mansoni: in vitro schistosomicidal activity of piplartine. Exp. Parasitol. 127, 357-364.

Michaels, R.M., Prata, A., 1968. Evolution and characteristics of Schistosoma mansoni eggs laid in vitro. J. Parasitol. 54, 921-930.

Newman, D.J., Cragg, G.M., 2012. Natural products as sources of new drugs over the 30 years from 1981 to 2010. J. Nat. Prod. 75, 311-335.
Paula, F.R., Serrano, S.H.P., Tavares, L.C., 2009. Aspectos mecanísticos da bioatividade e toxicidade de nitrocompostos. Quim. Nova 32, 1013-1020.

Pica-Mattoccia, L., Cioli, D., 2004. Sex- and stage-related sensitivity of Schistosoma mansoni to in vivo and in vitro praziquantel treatment. Int. J. Parasitol. 34 527-533.

Radke, M.G., Broome, P.B., Belanger, G.S., 1971. Schistosoma mansoni, mouse mortality test system for mass screening for prophylactic drugs. Exp. Parasitol. 30, 1-10.

Ramirez, B., Bickle, Q., Yousif, F., Fakorede, F., Mouries, M.A., Nwaka, S., 2007. Schistosomes: challenges in drug screening. Exp. Opin. Drug Dis. 2, 53-61.

Resende, F.A., Tomazella, I.M., Barbosa, L.C., Ponce, M., Furtado, R.A., Pereira, N.A Bastos, J.K., Silva, M.L.A., Tavares, D.C., 2010. Effect of the dibenzylbutyrolactone lignan (-)-hinokinin on doxorubicin and methyl methanesulfonate clastogenicity in V79Chinese hamster lung fibroblasts. Mut. Res. 700, 62-66.

Ribeiro-dos-Santos, G., Verjovski-Almeida, S., Leite, L.C., 2006. Schistosomiasis-a century searching for chemotherapeutic drugs. Parasitol. Res. 99, 505-521.

Rollinson, D., Knopp, S., Levitz, S., Stothard, J.R., Tchuenté, L.A., Garba, A. Mohammed, K.A., Schur, N., Person, B., Colley, D.G., Utzinger, J., 2013. Time to set the agenda for schistosomiasis elimination. Acta Trop. 128 (2), 423-440.

Royo, V.A., Santos, F.F., Souza, V.A., Pereira, A.C., Da Silva, R., Vinhólis, A.H.C. Donate, P.M., Silva, M.L.A., Albuquerque, S., Bastos, J.K., 2003. Biological activity evaluation of dibenzylbutyrolactone lignans derivatives against Leishmania braziliensis. Braz. J. Pharmacogn. 13, 18-21.

Sabah, A.A., Fletcher, C., Webbe, G., Doenhoff, M.J., 1986. Schistosoma mansoni: chemotherapy of infections of different ages. Exp. Parasitol. 61, 294-303.

Sanderson, L., Bartlett, A., Whitfield, P.J., 2002. In vitro and in vivo studies on the bioactivity of a ginger (Zingiber officinale) extract toward adult schistosomes and their egg production. J. Helminthol. 76, 241-247.

Saraiva, J., Veja, C., Rolon, M., Da Silva, R., Silva, M.L., Donate, P.M., Bastos, J.K., Gomez-Barrio, A., De Albuquerque, S., 2007. In vitro and in vivo activity of lignan lactones derivatives against Trypanosoma cruzi. Parasitol. Res. 100, 791-795.

Sayed, A.A., Simeonov, A., Thomas, C.J., Inglese, J., Austin, C.P., Williams, D.L., 2008. Identification of oxadiazoles as new drug leads for the control of schistosomiasis. Nat. Med. 14, 407-412.

Shuhua, X., Binggui, S., Chollet, J., Tanner, M., 2000. Tegumental changes in adult Schistosoma mansoni harboured in mice treated with praziquantel enantiomers. Acta Trop. 76, 107-117.

Silva, R., Souza, H.B., Silva, A.A., Souza, V.A., Pereira, A.C., Royo, V.A., Silva, M.L.A., 2005. Trypanocidal activity of (-)-cubebin derivatives against free amastigote forms of Trypanosoma cruzi. Bioorg. Med. Chem. Lett. 15, 303-307.

Silva, M.L., Coímbra, H.S., Pereira, A.C., Almeida, V.A., Lima, T.C., Costa, E.S., Vinhólis, A.H., Royo, V.A., Silva, R., Filho, A.A., Cunha, W.R., Furtado, N.A., Martins, C.H., Carvalho, T.C., Bastos, J.K., 2007. Evaluation of Piper cubeba extract (-)-cubebin and its semi-synthetic derivatives against oral pathogens. Phytother. Res. 21, 420-422.

Smithers, S.R., Terry, R.J., 1965. Infection of Laboratory hosts with cercariae of Schistosoma mansoni and the recovery of adult worms. Parasitololgy 55 695-700.

Steinmann, P., Keiser, J., Bos, R., Tanner, M., Utzinger, J., 2009. Schistosomiasis and water resources development, systematic review meta-analysis and estimates of people at risk. Lancet Infect. Dis. 6, 411-425.

Usia, T., Watabe, T., Kadota, S., Tezuka, Y., 2005. Potent CYP3A4 inhibitory constituents of Piper cubeba. J. Nat. Prod. 68, 64-68.

Van der Werf, M.J., De Vlas, S.J., Brooker, S., Looman, C.W., Nagelkerke, N.J., Habbema, J.D., Engels, D., 2003. Quantification of clinical morbidity associated with schistosome infection in sub-Saharan Africa. Acta Trop. 86, 125-139.

Xiao, S.H., Keiser, J., Chollet, J., Utzinger, J., Dong, Y., Endriss, Y., Vennerstrom, J.L., Tanner, M., 2007. In vitro and in vivo activities of synthetic trioxolanes against major human Schistosome species. Antimicrob. Agents. Chemother. 51, 1440-1445.

Wang, W.L., Song, L.J., Chen, X., Yin, X.R., Fan, W.H., Wang, G.P., Yu, C.X., Feng, B., 2013. Synthesis and SAR studies of praziquantel derivatives with activity against Schistosoma japonicum. Molecules 18 (8), 9163-9178. 